\title{
Intramural chondroid hamartoma in the distal esophagus in an adult: A case report and review of the literature
}

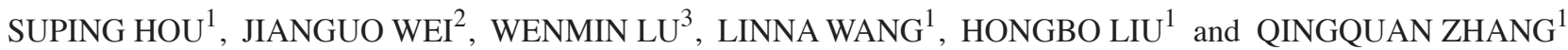 \\ ${ }^{1}$ Department of Pathology, Harrison International Peace Hospital, Hengshui, Hebei 053000; ${ }^{2}$ Department of Pathology, \\ Shaoxing People's Hospital, Shaoxing, Zhejiang 312000; ${ }^{2}$ Department of Thoracic Surgery, \\ Harrison International Peace Hospital, Hengshui, Hebei 053000 P.R. China
}

Received July 24, 2016; Accepted October 13, 2016

DOI: $10.3892 /$ mco.2016.1095

\begin{abstract}
Hamartoma of the esophagus is a rare lesion and the number of cases reported in the literature to date is limited. The majority of hamartomas are intraluminal tumors located in the upper third of the esophagus. Histopathologically, the majority of these tumors comprise a mixture of adipose tissue, skeletal/smooth muscle tissue, vascular components and fibrous connective tissue. We herein present the case of a 33-year-old man with an intramural chondroid hamartoma located in the lower third of the esophagus. The patient underwent esophagotomy and the histopathological examination revealed that the tumor was mainly composed of chondroid tissue $(60 \%)$ admixed with adipose tissue $(25 \%)$ and fibrous connective tissue $(15 \%)$. The aim of this study was to describe another variant of esophageal hamartoma, which exhibits a versatile phenotype.
\end{abstract}

\section{Introduction}

Benign tumors of the esophagus are rare, accounting for $<1 \%$ of all esophageal neoplasms. Leiomyomas are the most common benign esophageal tumors, whereas hamartomas are the rarest benign tumors (1). To the best of our knowledge, there are only 12 cases of esophageal hamartoma reported in the English literature to date, of which 8 were located in the upper third and only 2 were in the lower third of the esophagus no information regarding location was available for the remaining 2 cases. One of the tumors was intramural, whereas in all the remaining cases the tumors protruded into the lumen (2). However, esophageal chondroid hamartoma has never been reported. We herein present an extremely rare case of an adult patient presenting with an intramural chondroid hamartoma located in the lower

Correspondence to: Dr Suping Hou, Department of Pathology, Harrison International Peace Hospital, 180 Renmin East Road, Hengshui, Hebei 053000, P.R. China

E-mail: housuping2008@163.com

Key words: chondroid hamartoma, esophagus, adult, intramural tumor, surgery third of the esophagus and describe the diagnosis and management of isolated esophageal chondroid hamartomas.

\section{Case report}

A 33-year-old male patient was admitted to the Department of Thoracic Surgery of the Harrison International Peace Hospital (Hengshui, China) in August, 2013, with epigastric pain, difficulty in swallowing and occasional vomiting after eating. The symptoms were aggravated and the patient developed dysphagia, occasionally experiencing acid reflux and heartburn within the last 2 months. Barium swallow examination revealed narrowing of the lumen of the distal esophagus. Upper endoscopy revealed two diverticulum-like lesions, measuring $0.3 \times 0.3 \times 0.3$ and $0.3 \times 0.3 \times 0.3 \mathrm{~cm}$, located on the right anterior wall of the esophagus at a distance of $\sim 38 \mathrm{~cm}$ from the incisors, and one diverticulum-like lesion measuring $1.0 \times 1.0 \times 0.8 \mathrm{~cm}$, located at $39-40 \mathrm{~cm}$ from the incisors. A biopsy from the latter lesion revealed that the tissue was lined by stratified squamous epithelium and the stroma was infiltrated by chronic and acute inflammatory cells.

Intraoperatively, the affected segment of the distal esophagus contained a mass measuring $2.0 \times 2.0 \times 2.0 \mathrm{~cm}$ located at $2.0 \mathrm{~cm}$ from the cardia. The mass tightly adhered to the esophageal mucosa. On gross examination, the excised esophageal specimen measured $3.5 \times 3.0 \times 1.5 \mathrm{~cm}$ and included a mass measuring $2.0 \times 1.5 \times 1.5 \mathrm{~cm}$ lying directly underneath the mucosa. On cross-section, the mass was grayish-white and had a hard consistency (Fig. 1).

On microcopic examination, the mass was lined by squamous epithelium and the stroma was mainly composed of chondroid tissue $(60 \%)$ admixed with adipose tissue $(25 \%)$ and fibrous connective tissue (15\%) (Fig. 2). The final histopathological diagnosis was lower esophageal chondroid hamartoma. There was no recurrence of the tumor during 2 years of postoperative follow-up (last follow-up was in September, 2015).

Informed consent was obtained from the patient regarding the publication of the case details and associated images.

\section{Discussion}

Hamartoma is defined as a non-neoplastic, uni- or multifocal developmental malformation, comprising a mixture 
of cytologically normal mature cells and tissues which are indigenous to the anatomic location, exhibiting a disorganized architectural pattern with predominance of one of its components (3-6). Hamartomas may occur in any organ, but are most commonly located in the lungs (7), liver (8), pancreas (9) and spleen (10); however, they are rare in the esophagus. The majority of the esophageal hamartomatous lesions have been reported in pediatric patients (2), with a few cases reported in the adult population, mostly among men.

Esophageal hamartomas are classified based on their location in relation to the esophageal wall as intramural, extramural or intraluminal (1). In previously reported cases, the hamartoma was most commonly found in the upper third of the esophagus and belonged to the category of intraluminal lesions. In the present case, the tumor was located in the lower third of the esophagus and was intramural. Smith et al (11) reported a case in which the tumor arose in the lower third of the esophagus and was intramurally located; the patient was a 3.5-year-old female and the tumor consisted of small mature lymphocytes, acidophilic histiocytes, cartilage and bronchial-like mucous glands. In the present case, however, the patient was a 33-year-old man and the tumor mainly consisted of chondroid tissue admixed with adipose and fibrous connective tissue. Following a review of the literature (Table I), it is noteworthy that the tumors arising in the upper third of the esophagus were all intraluminal, whereas those in the lower third of the esophagus were mostly intramural. Due to its rarity, there are no epidemiological data regarding the occurrence of this type of tumor in the esophagus.

Hamartomas are pathologically subclassified according to the relative abundance of a particular endogenous tissue component, and the variants described include chondroid, chondromesenchymal, angiomatous, lipomatous and leiomyomatous hamartomas (12). A review of the previously reported cases (Table I) shows that the majority of the tumors comprise a mixture of adipose tissue, skeletal muscle tissue and vascular components embedded in connective tissue. However, the tumor in this case was mainly composed of chondroid tissue admixed with adipose and fibrous connective tissue. As the mesenchymal component in this lesion was represented by chondroid cells, we recommend the term "chondroid hamartoma' to denote this unique characteristic of the tumor. Although several chondroid hamartomas have been reported in the lung and liver $(13,14)$, to the best of our knowledge none have been reported in the esophagus to date. Our findings add another variant to the versatile phenotype of esophageal hamartoma.

There are no tumor markers or imaging characteristics that allow a definitive preoperative diagnosis of esophageal hamartoma, and the majority of the cases are diagnosed following surgical resection or at autopsy. The diagnosis is based entirely on histopathological evaluation. The differential diagnosis includes choristoma and teratoma. Hamartoma is an overgrowth of mature tissues that normally occur in an expected area or organ, but with disorganization and often with one element predominating (15). Choristoma is a mass consisting of tissue that is histologically normal for an organ or part of the body other than the one in which it is located (15). Choristoma is considered to consist of mass-forming, irregular and heterotopic tissue (15). Mature teratomas may have no mitoses or

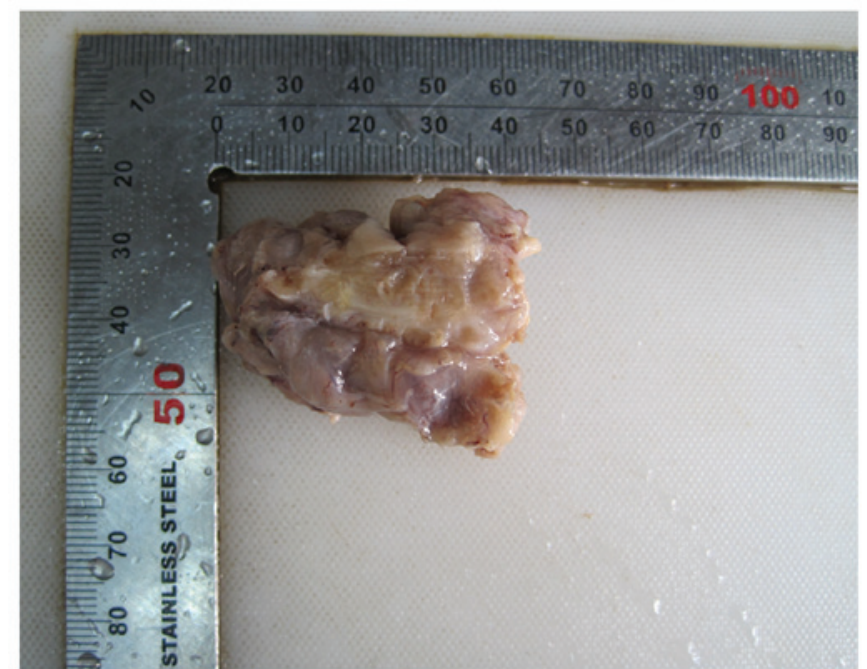

Figure 1. On macroscopic examination, a mass lying directly underneath the esophageal mucosa was identified. On cross-section, the mass was grayish-white and of hard consistency.

a low mitotic index, they are mass-forming lesions and may comprise heterologous elements, such as skeletal muscle, cartilage or adipose tissu; however, teratomas are predominantly composed of epidermal, dermal and adnexal structures along with keratin, rather than cartilaginous elements. Thus, our case was ultimately diagnosed as chondroid hamartoma.

Esophageal intramural hamartomas are associated with non-specific, vague symptoms or are asymptomatic, presenting in late childhood or adulthood. We hypothesize that the lack of symptoms is the result of the significant compliance of the esophagus. Symptoms may occur late during the course of the disease as the result of the slow, gradual growth of these tumors, combined with the indolent nature of these lesions, which is also common among other benign tumors and may remain undetected for years (1). The clinical and pathological characteristics of 13 cases of esophageal hamartomas, including the present case, are summarized in Table I (additional full text for 2 cases was not available). The median age of the patients was 31.3 years (range, infancy-61 years) and the male:female ratio was $3: 1$. The clinical manifestations of the esophageal hamartoma include dysphagia, mid chest/epigastric pain, vomiting and weight loss. Our patient was admitted due to epigastric pain, difficulty in swallowing and occasional vomiting after eating. Upper endoscopy revealed three diverticulum-like lesions and the patient underwent esophagotomy. Surgical resection is the standard treatment for hamartomas, without reported recurrences, and with a good prognosis. The procedure is usually performed via esophagotomy or thoracotomy, whereas for some tumors with thin pedicles, endoscopic excision may be the preferable approach. In the previously reported cases, 9 of the patients underwent esophagotomy $(2,11,16-22)$ and 1 patient underwent snare coagulation (23). In the present case, we were able to follow up the patient for 2 years, during which time there was no evidence of tumor recurrence.

In conclusion, the esophageal tumor in the present case was mainly composed of chondroid tissue and, in such cases, chondroid hamartoma of the esophagus should be considered in the differential diagnosis. 
Table I. Characteristics of cases with esophageal hamartoma previously reported in the literature.

\begin{tabular}{llll}
\hline Study, year & Age (years)/gender & Location & Microscopic appearance \\
\hline
\end{tabular}

Fuller, 1963

Shah et al, 1975

Smith et al, 1976

3.5/female

Kafai and Mirbod, 1977

Beckerman et al, 1980

Child/male

Infant/male

Venn et al, 1985

52/male

Gupta et al, 1987

10/male

Saitoh et al, 1990

40/female

30/female

Lakhkar et al, 1991

Bernat et al, 1993

Halfhide et al, 1995

NA

41/male

Upper esophagus/

intraluminal

Upper esophagus/

intraluminal

Upper esophagus/

intraluminal

Upper end of esophagus/

intraluminal

Upper esophagus/ intraluminal

Upper esophagus/ intraluminal

NA

Distal one-third of esophagus/intraluminal

Present case
Distal one-third of esophagus/intramural
Fibro-adipose connective tissue

admixed with mucous glands

Adipose tissue, glandular structures

and cartilaginous tissue

Small mature lymphocytes,

acidophilic histiocytes, cartilage,

bronchial-like mucous glands

NA

Skeletal muscle fibres, fibrous

connective tissue and hyaline cartilage

Polypoid esophageal hamartoma

Adipose tissue, fibres of skeletal tissue, collagen tissue and moderate vascularity

Osseous, cartilaginous, fibrous and adipose tissue and glandular structures

Squamous epithelium, hyperplastic and cystic glands with abundant well vascularized stroma

\section{NA}

Fat cells, fibrous tissue, atypical blood vessels and a large solitary island of bone enclosed by periosteum

NA

Cartilaginous tissue, adipose tissue and fibrous connective tissue

NA, information not available.
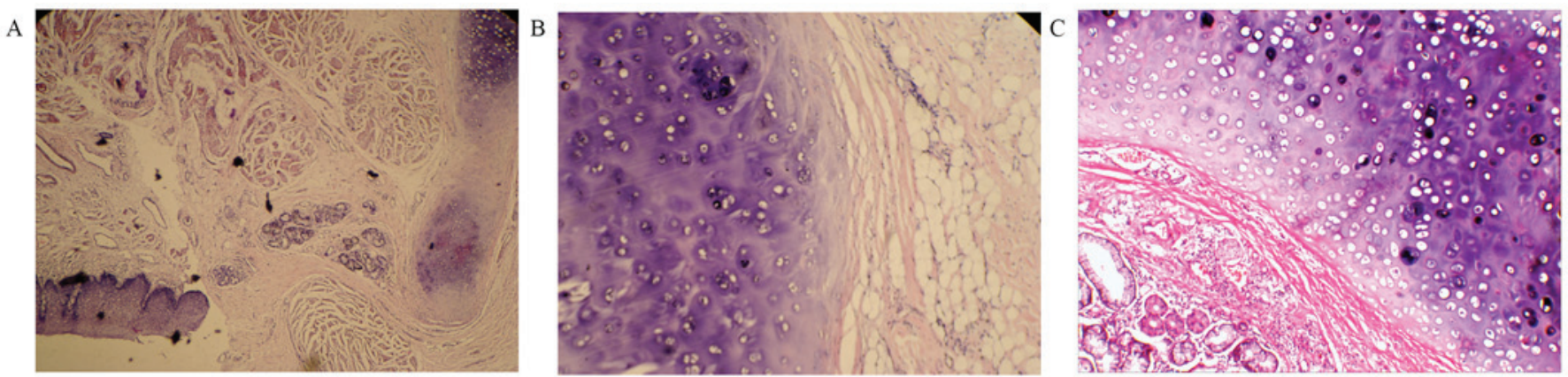

Figure 2. (A) Microscopically, the mass was lined by squamous epithelium [hematoxylin and eosin staining (H\&E); magnification, $\mathrm{x} 40$ ]. (B) The stroma was mainly composed of chondroid tissue admixed with adipose tissue (H\&E; magnification, x100) and (C) fibrous connective tissue (H\&E; magnification, $\mathrm{x} 200$ ).

\section{References}

1. Choong CK and Meyers BF: Benign esophageal tumors: Introduction, incidence, classification and clinical features. Semin Thorac Cardiovasc Surg 15: 3-8, 2003.
2. Wu WM, Wang XD, Sun G, Qiang LH and Yang YS: Adult asymptomatic hamartoma in the distal esophagus: A rare case. Intern Med 53: 1945-1948, 2014.

3. Pilch BZ (ed): Larynx and hypopharynx. In: Head and Neck Surgical Pathology. Lippincott Williams and Wilkins, Philadelphia, PA, pp230-83, 2001. 
4. Barnes L: Surgical Pathology of the Head and Neck. Vol. 2. 2nd edition. Marcel Dekker, New York, NY, pp1649-1672, 2001.

5. Kumar V, Abbas AK and Aster JC (eds): Robbins Basic Pathology. 9th edition. Philadelphia, USA, Saunders, Elsevier, pp257, 2013.

6. Allon I, Allon DM, Hirshberg A, Shlomi B, Lifschitz-Mercer B and Kaplan I: Oral neurovascularhamartoma: A lesion searching for a name. J Oral Pathol Med 41: 348-353, 2012.

7. Umashankar T, Devadas AK, Ravichandra G and Yaranal PJ: Pulmonary hamartoma: Cytologicalstudy of a case and literature review. J Cytol 29: 261-263, 2012.

8. Rosado E, Cabral P, Campo M and Tavares A: Mesenchymal hamartoma of the liver-a case report and literature review. J Radiol Case Rep 7: 35-43, 2013.

9. Kawakami F, Shimizu M, Yamaguchi H, Hara S, Matsumoto I, $\mathrm{Ku}$ Y and Itoh T: Multiple solid pancreatic hamartomas: A case report and review of the literature. World J Gastrointest Oncol 4 : 202-206, 2012

10. Basso SM, Sulfaro S, Marzano B, Fanti G, Chiara GB and Lumachi F: Incidentally discovered asymptomatic splenic hamartoma with rapidly expansive growth: A case report. In Vivo 26: 1049-1052, 2012.

11. Smith CW, Murray GF and Wilcox BR: Intramural esophageal hamartoma. An unusual cause of progressive stricture in a child. J Thorac Cardiovasc Surg 72: 315-318, 1976.

12. Park SK, Jung H and Yang YI: Mesenchymal hamartoma in nasopharynx: A case report. Auris Nasus Larynx 35: 437-439, 2008.

13. Fan M, Lin Y and Liu L: Multiple pulmonary chondroid hamartoma. J Thorac Oncol 9: 11053-11054, 2014.

14. Scheele J, Lemke J, Barth TF, Juchems M, Wittau M, Kornmann $\mathrm{M}$ and Henne-Bruns D: Chondroid hamartoma of the liver. GMS Interdiscip Plast Reconstr Surg DGPW 17: Doc16, 2014
15. Dorland and Newman WA: Dorland's illustrated medical dictionary. 32nd edition. Elsevier/Saunders, Philadelphia, 2012.

16. Fuller AP: Pedunculated hamartoma of the oesophagus. J Laryngol Otol 77: 706-713, 1963.

17. Shah B, Unger L and Heimlich HJ: Hamartomatous polyp of the esophagus. Arch Surg 110: 326-328, 1975.

18. Beckerman RC, Taussig LM, Froede RC, Coulthard SW, Firor H and Tonkin I: Fibromuscular hamartoma of the esophagus in an infant. Am J Dis Child 134: 153-155, 1980.

19. Venn GE, DaCosta P and Goldstraw P: Giant oesophageal hamartoma. Thorax 40: 684-685, 1985.

20. Gupta AK, Goyal VP, Hemani DD, Maheshwari SK and Dubey MK: Pedunculated intraluminal oesophageal hamartoma. J Laryngol Otol 101: 851-854, 1987.

21. Saitoh Y, Inomata Y, Tadaki N and Mimaki S: Pedunculated intraluminal osteochrondromatous hamartoma of the esophagus. J Otolaryngol 19: 339-342, 1990.

22. Lakhkar BN, Ghosh MK, Shenoy PD and Patil UD: Hamartoma-a benign intraluminal tumor of the oesophagus (a case report). J Postgrad Med 37: 235-237, 236A-236B, 1991.

23. Halfhide BC, Ginai AZ, Spoelstra HA, Dees J and Vuzevski VD Case report: A hamartoma presenting as a giant oesophageal polyp. Br J Radiol 68: 85-88, 1995.

24. Kafai $F$ and Mirbod P: Hamartoma of the oesophagus. Br J Clin Pract 31: 154-156, 1977

25. Bernat M, Strutyńska-Karpinska M, Lewandowski A, Blaszczuk J, Grabowski K and Czapla L: Benign esophageal tumors. Wiad Lek 46: 24-27, 1993 (In Polish). 